Pesq. Vet. Bras. 36(2):94-102, fevereiro 2016

DOI: $10.1590 / \mathrm{S} 0100-736 \mathrm{X} 2016000200006$

\title{
Bases ósseas e musculares do corte comercial de pescoço de jacaré-do-pantanal (Caiman yacare Daudin, 1802) ${ }^{1}$
}

\begin{abstract}
Sandra I.S. Figueiredo ${ }^{2 *}$, Luciana B.M. Araújo ${ }^{3}$, Rosa H.S. Ferraz ${ }^{2}$ e Eugênio G. Araújo ${ }^{3}$
ABSTRACT.- Figueiredo S.I.S., Araújo L.B.M., Ferraz R.H.S. \& Araújo E.G. 2016. [Bone and muscular bases of commercial cut from the neck of Yacare Caiman (Caiman yacare Daudin, 1802).] Bases ósseas e musculares do corte comercial do pescoço de jacaré-do-pantanal (Caiman yacare Daudin, 1802). Pesquisa Veterinária Brasileira 36(2):94-102. Departamento de Ciências Básicas e Produção Animal, Faculdade de Agronomia, Medicina Veterinária e Zootecnia, Universidade Federal de Mato Grosso, Avenida Fernando Corrêa da Costa 2367, Cidade Universitária, Boa Esperança, Cuiabá, MT 78060-900, Brazil. E-mail: sandrafigueiredovet@gmail.com

The yacare Caiman (Caiman yacare) is an abundant species in the Pantanal ecosystem. Commercial exploitation was regulated in 1990 and has become a thriving business. In order to fulfill this demand, a processing plant settled in Mato Grosso state, Brazil, has been supplying for the last four years different cuts of Pantanal Caiman meat, including the "file de dorso" (back sirloin) obtained from the neck. The aim of this study was to describe the muscles and corresponding bones related to this cut. To describe the bones, we used six boned carcasses from juvenile yacare Caiman, as well as an adult specimen obtained after animal death, by donation from the Federal University of Mato Grosso Zoo. The bones were macerated in water, bleached with 10 volume-hydrogen-peroxide solution, and their anatomical details were recorded. In order to describe the muscles, 24 juvenile specimens were obtained after slaughter and skinning, preserved in a freezer at $-20^{\circ} \mathrm{C}$, and thawed at the time of use, without any fixation. After evisceration, the specimens were dissected on both sides to verify symmetry of structures, muscle attachments, sintopy relations, shape, and muscular architecture. The cervical spine of $C$. yacare features nine cervical vertebrae (CV) associated to their ribs, serving as the main base for the back sirloin cut, which is formed by neck muscles, except for the intertransverse cervical and external intercostal cervical muscles.
\end{abstract}

INDEX TERMS: Yacare Caiman, Caiman yacare, Alligatoridae, caiman production, morphology, muscles, back sirloin cut.

RESUMO.- O jacaré-do-pantanal (Caiman yacare) é uma espécie abundante no ecossistema do Pantanal. Sua exploração comercial está regulamentada desde 1990 e se tornou um agronegócio em expansão. Para atender essa demanda, uma unidade processadora instalada em Mato Grosso, vem

\footnotetext{
${ }^{1}$ Recebido em 26 de agosto de 2015.

Aceito para publicação em 7 de novembro de 2015

${ }^{2}$ Departamento de Ciências Básicas e Produção Animal, Faculdade de Agronomia, Medicina Veterinária e Zootecnia, Universidade Federal de Mato Grosso (UFMT), Av. Fernando Corrêa da Costa 2367, Cidade Universitária, Boa Esperança, Cuiabá, MT 78060-900, Brasil. *Autor para correspondência: sandrafigueiredovet@gmail.com

${ }^{3}$ Departamento de Medicina Veterinária, Escola de Veterinária e Zootecnia, Universidade Federal de Goiás (UFG), Campus Samambaia, Rodovia Goiânia-Nova Veneza, Cx. Postal 131, Goiânia, GO 74001-970, Brasil.
}

comercializando carne de jacaré em diferentes cortes, entre os quais o filé de dorso, oriundo do pescoço, nos últimos quatro anos. 0 objetivo desta pesquisa foi descrever os músculos e correspondentes bases ósseas desse corte. Para a descrição de ossos, utilizaram-se seis carcaças desossadas de exemplares juvenis de jacaré-do-pantanal, além de um exemplar adulto obtido após morte do animal, por doação, do Zoológico da UFMT. Os ossos foram macerados em água corrente, clareados com solução de água oxigenada a 10 volumes, e seus detalhes anatômicos foram descritos. Para descrever o músculo, 24 exemplares juvenis foram obtidos após abate e esfola, conservados em freezer e descongelados quando utilizados, sem qualquer fixação. Após a evisceração, foram dissecados em ambos os antímeros, para verificação de simetria de ocorrência, fixações mus- 
culares, relacões de sintopia, forma e arquitetura muscular. Verificou-se que a coluna cervical em $C$. yacare apresenta nove vértebras cervicais (VC), associadas com as respectivas costelas, que servem de base principal ao filé de dorso, que é constituído pela musculatura cervical, exceto os músculos intertransversais cervicais e intercostais cervicais externos.

TERMOS DE INDEXAÇÃO: Jacaré-do-pantanal, Caiman yacare, Alligatoridae, crocodilicultura, filé de dorso, morfologia, musculatura.

\section{INTRODUÇÃO}

Em Mato Grosso, a carne de jacaré-do-pantanal tem sido comercializada desde 1992. Em 2008, houve a instalação da única unidade processadora dessa espécie com obtenção do selo do Serviço de Inspeção Federal (SIF) na América Latina, o que possibilitou a comercialização no mercado nacional e internacional (Romanelli et al. 2002, Piran 2010). Essa unidade, no período de 2009 a 2012, comercializou aproximadamente $14 \mathrm{mil} \mathrm{kg}$ de carne, dos quais nove mil kg oriundos da região cervical (SFA/MT 2013), cuja musculatura constitui o filé de dorso que, junto aos filés do tronco e da cauda, tem maior valorização comercial no varejo em relação aos cortes dos membros (COOCRIJAPAN 2013).

No entanto, a carência de informações referentes aos cortes comerciais limita o incremento da comercialização sistematizada, pois não atende às normas brasileiras de rotulagem (Rodrigues et al. 2007). Para tal, necessário se faz a caracterização dos músculos e respectivas bases ósseas que compõem esse corte comercial, com vistas ao estabelecimento de parâmetros que possibilitem melhor aproveitamento do recurso.

O objetivo deste artigo foi descrever os músculos e ossos que constituem o corte filé de dorso, único da região cervical de C. yacare.

\section{MATERIAL E MÉTODOS}

O projeto foi cadastrado no Sistema de Autorização e Informação em Biodiversidade - SISBIO (23717-1) e aprovado pelo Comitê de Ética em Pesquisa Animal, Universidade Federal de Mato Grosso (23108.018396/10-7).

Para a descrição dos ossos, utilizou-se um espécime de Caiman yacare adulto, obtido por doação, após óbito do animal, do Zoológico da UFMT, além de seis carcaças desossadas de juvenis. Para a caraterização dos músculos, utilizaram-se 24 espécimes de juvenis, obtidos de criatório localizado no município de Cáceres (MT), que apresentavam, em média, dois anos e meio de idade, 4 kg de massa corporal e de 35 a $40 \mathrm{~cm}$ de circunferência abdominal; este último critério foi utilizado para definir o momento do abate.

Para o processamento ósseo, realizou-se a desarticulação e identificação dos ossos, previamente ao processo de maceração em água corrente, além de clareamento em solução de água oxigenada a 10 volumes e secagem à temperatura ambiente e à sombra. As partes com tecido fibroso ou cartilaginoso foram fixadas em solução aquosa de formaldeído a $10 \%$, dissecadas e submetidas à técnica de glicerinação de Giacomini (Silva et al. 2008). Os ossos do animal adulto, após o processamento, foram sequenciados para a montagem do esqueleto.

Para a dissecção dos músculos, em ambos os antímeros, os animais obtidos do frigorífico foram mantidos congelados para posterior dissecção a fresco. Após a evisceração, realizou-se a dissecção dos músculos com o auxílio de lupa de pala e lupa circular de luz fria. As vértebras e costelas torácicas, o esterno, o coracoide, o hioide, o basioccipital e o exoccipital foram também descritos, por serem ancoragem para alguns músculos cervicais. As inserções na cabeça de alguns músculos cervicais não foram descritas, em razão da secção na articulação atlanto-occipital, como forma de sangria no processo de abate.

Para a adequada utilização dos termos anatômicos, estabeleceu-se a posição anatômica de C. yacare, que apresenta posição quadrupedal, com a cabeça, pescoço, tronco e cauda dispostos longitudinalmente e paralelos em relação ao solo. A cabeça é voltada para o horizonte, e os quatro membros e a cauda são apoiados no solo. Nas descrições e discussões dos resultados, priorizou-se o uso da literatura disponível sobre crocodilianos; na ausência dela, utilizaram-se informações sobre anfíbios, outros répteis viventes e extintos e aves.

A ausência de padronização da terminologia anatômica para os répteis levou à adoção de uma combinação dos sistemas de termos anatômicos existentes - a Nomina Anatomica Veterinaria NAV (ICVGAN 2012) e a Nomina Anatomica Avium - NAA (Baumel et al. 1993). Os resultados ósseos e musculares foram documentados por meio de fotografias obtidas com câmera Nikon D90, com uma lente de $35 \mathrm{~mm} 1.8$ e outra de $60 \mathrm{~mm} \mathrm{2.8,} \mathrm{e} \mathrm{flashes} \mathrm{de} \mathrm{estúdio,}$ sem fio.

\section{RESULTADOS}

Nos espécimes analisados, não se observou variação anatômica entre os indivíduos e, tampouco, entre os antímeros, tanto para os ossos quanto para os músculos.

\section{Bases ósseas do filé de dorso}

Constituem essa base as vértebras e costelas cervicais, as vértebras e costelas torácicas, o esterno, o coracoide, 0 hioide, o basioccipital e o exoccipital.

Vértebras e costelas cervicais. A coluna vertebral de C. yacare é constituída por cinco regiões diferenciadas. A região cervical possui nove vértebras cervicais (VC), em que a primeira $\mathrm{VC}$, denominada atlas, é uma vértebra atípica. A segunda é denominada áxis, e as demais - da terceira à nona - foram descritas em conjunto por apresentarem características similares (Fig.1). 0 atlas consiste de quatro partes, uma dorsal chamada de pró-atlas, uma ventral e duas partes laterais ou massas laterais (Fig.2). 0 áxis possui um corpo alongado, arco e processos (articular e espinhoso). Nos animais juvenis, o terço cranial do corpo do áxis constitui uma porção demarcada do restante do corpo, sobre o qual repousa o rudimentar processo odontoide. Os dois terços caudais do corpo apresentam uma crista ventral e um discreto processo ventral, e sua extremidade caudal é convexa. A superfície lateral da extremidade cranial do corpo possui uma projeção semicircular, com duas áreas articulares (uma dorsal para fixação do tubérculo da $2^{\text {a }}$ costela cervical, e outra ventral para a cabeça da mesma costela) (Fig.2).

As vértebras cervicais da terceira a nona apresentam um corpo cilíndrico, cuja extremidade cranial é côncava, e a caudal, convexa. Na superfície lateroventral do corpo vertebral, em posição paramediana, há uma projeção que serve para fixação da cabeça da costela cervical correspondente. Essa superfície articular torna-se maior e desloca-se 


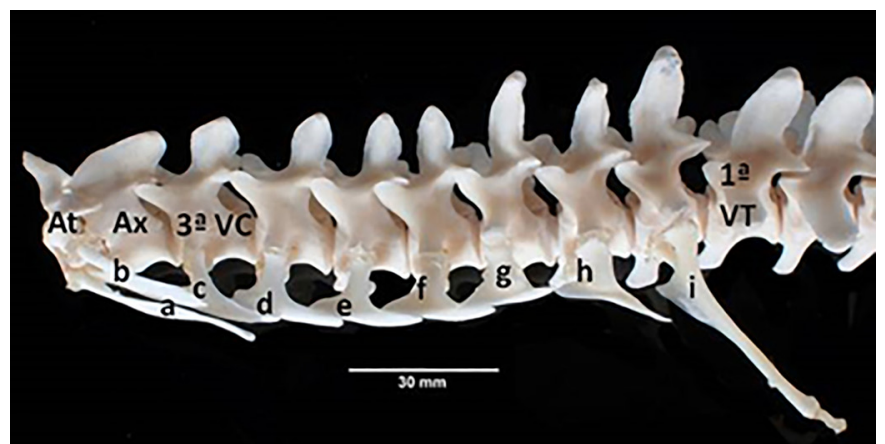

Fig.1. Vértebras e costelas cervicais, $1^{\underline{a}}$ e $2^{\mathrm{a}}$ vértebras torácicas de Caiman yacare juvenil, vista lateral esquerda. Atlas (At), áxis $(\mathrm{Ax}), 3^{\mathrm{a}}$ vértebra cervical $\left(3^{\mathrm{a}} \mathrm{VC}\right), 1^{\underline{a}}$ vértebra torácica $\left(1^{\mathrm{a}} \mathrm{VT}\right)$, $1^{\text {a }}$ a $9^{\text {a }}$ costela cervical esquerda (a-i).

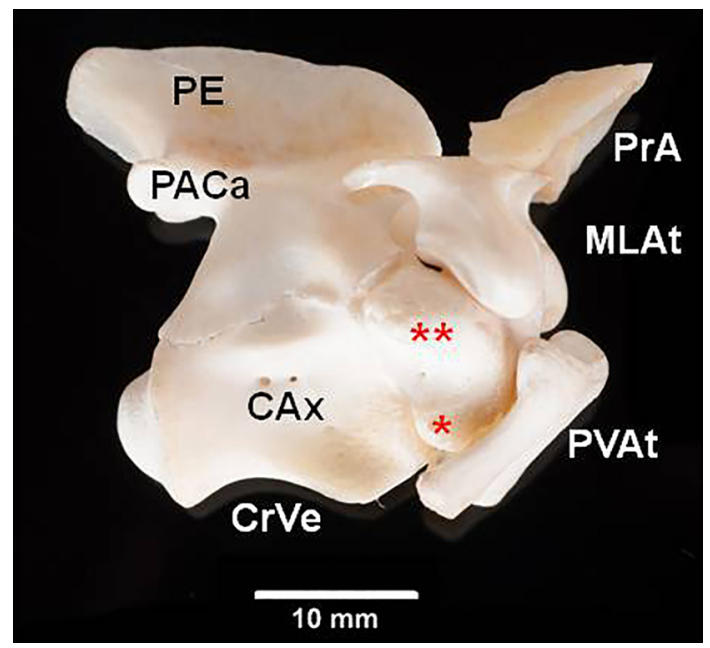

Fig.2. Atlas e áxis articulados de Caiman yacare juvenil, vista lateral direita. Atlas (pró-atlas (PrA), massa lateral (MLt), parte ventral do atlas (PVAt). Áxis (corpo do áxis (CAx), crista ventral (CrVe), face articular para a cabeça $(*)$ e tubérculo da costela cervical ${ }^{* *}$ ), processo articular caudal (PACa), processo espinhoso (PE).

laterodorsalmente em sentido caudal. A partir da terceira VC, observa-se na superfície ventral do corpo, na extremidade cranial da crista ventral, uma projeção laminar denominada processo ventral, que aumenta progressivamente de tamanho nas vértebras sequenciais e se projeta ventrocranialmente. Nessas vértebras, os processos articulares craniais possuem superfície articular voltada dorsomedialmente, e os caudais, ventrolateralmente. 0 processo transverso é único, dirigido lateroventralmente, e possui uma área articular plana (fóvea costal do processo transverso) para fixação do tubérculo da costela cervical. 0 processo espinhoso é bem desenvolvido e, na sétima, oitava e nona VC, apresenta o ápice bífido e rugoso.

Todas as VC têm costelas pareadas (Fig.1) - a primeira, a segunda e a nona de forma distinta entre si -, enquanto as demais têm características similares. A primeira costela cervical é alongada, achatada dorsoventralmente e com a superfície dorsal côncava. É uma projeção única, que se articula com a parte ventral do atlas em um só local, dirigindo-se caudalmente até atingir VC3. A segunda costela cervical apresenta o formato da letra Y, com duas superfícies articulares: o tubérculo (dorsalmente) e a cabeça (ventralmente). A haste maior, única, dirige-se caudoventralmente, estendendo-se até VC3. A nona e última costela cervical se estende lateralmente e se assemelha a uma costela torácica, com pequena cartilagem costal, porém, não se articula com o esterno. As demais costelas cervicais (da terceira à oitava) são constituídas de um eixo principal, cuja projeção cranial é menor e se acopla com a projeção caudal (maior) da costela antecedente e, assim, sucessivamente. Desse eixo principal, emergem em sentido medial, duas projeções ósseas articulares, uma disposta dorsalmente (tubérculo) e outra ventralmente (cabeça), com um bem marcado canal entre eles. A cabeça se articula com um curto processo do corpo, e o tubérculo se articula com o processo transverso da vértebra cervical correspondente.

Vértebras e costelas torácicas. Nove vértebras torácicas (VT) estão presentes no C. yacare. As duas primeiras VT constituem pontos de fixação para o músculo transverso espinhal cervical, e as cinco primeiras VT e respectivas costelas servem de pontos de fixação para o músculo longo do pescoço e são descritas a seguir.

As VT são vértebras típicas, procélicas, com corpo cilíndrico, cuja superfície ventral, nas quatro primeiras vértebras, apresenta o processo ventral. Apresentam processo

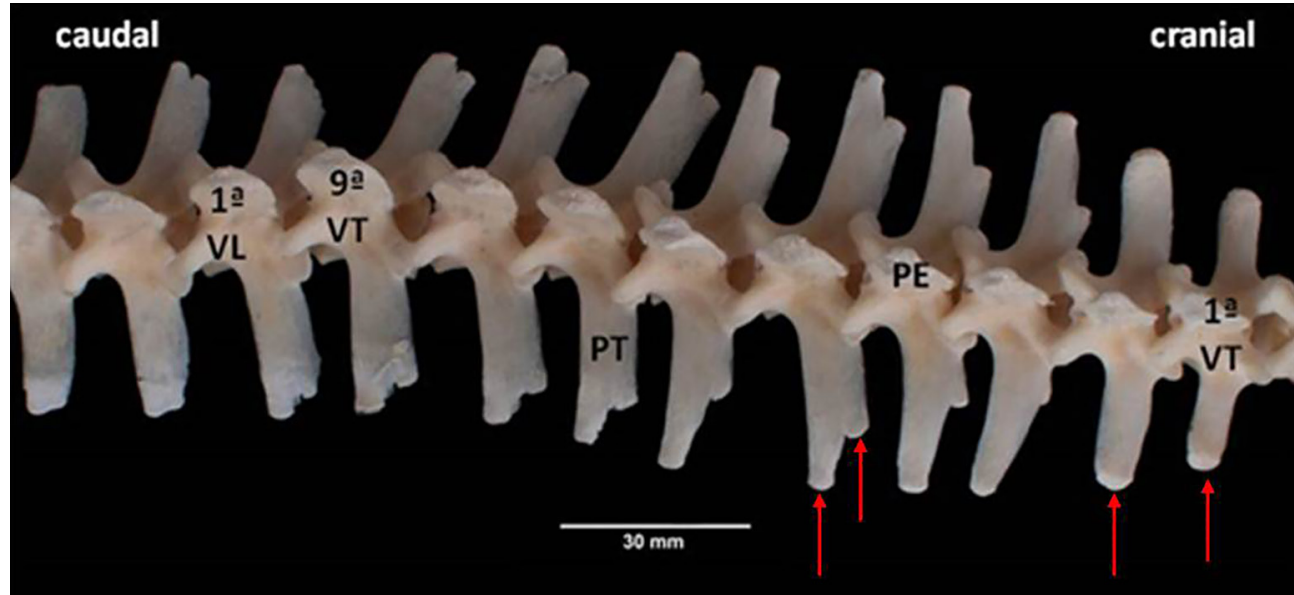

Fig.3. Vértebras torácicas e lombares de Caiman yacare juvenil, vista dorsal. 1av vértebra torácica (1 $\left.1^{\mathrm{a}} \mathrm{VT}\right)$, processo espinhoso (PE), processo transverso (PT) com fóveas costais (setas), 9avér-

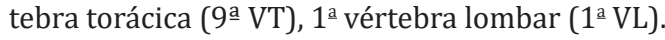


espinhoso bem desenvolvido, processos articulares (craniais e caudais) e processos transversos alongados e achatados dorsoventralmente, com a extremidade lateral única nas duas primeiras VT e bífido nas demais, com áreas para articulação com as costelas torácicas (Fig.3).

Esterno. 0 esterno é predominantemente cartilaginoso e constituído pelo episterno, o esterno cartilaginoso e os cornos xifoides. 0 episterno é sua porção mais cranial, uma projeção óssea mediana, cilíndrica e alongada. 0 esterno cartilaginoso tem aspecto quadrangular, e suas margens laterais têm duas superfícies articulares, destinadas à face articular da margem medial da asa do coracoide e para articulação com o primeiro par de costelas torácicas. Os cornos xifoides consistem de duas projeções cartilaginosas, alongadas, que contatam cranialmente com a porção caudal do esterno cartilaginoso e divergem gradualmente em sentido caudal. A margem medial une-se ao contralateral no plano mediano, e sua margem lateral tem incisuras costais para articulação com os segmentos esternais das demais costelas torácicas. Entre os dois cornos, há uma projeção na parte caudal (Fig.4).

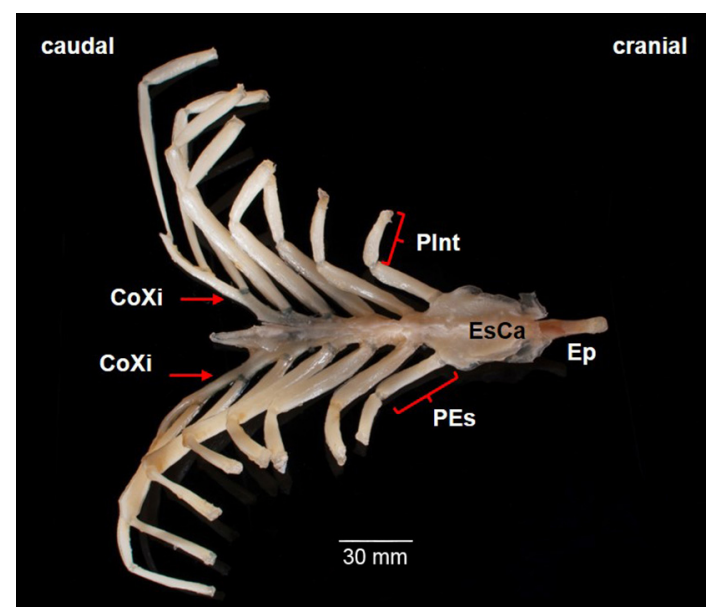

Fig.4. Esterno, porções esternais e intermediárias das costelas torácicas de Caiman yacare juvenil, vista dorsal. Corno xifoide (CoXi), episterno (Ep), esterno cartilaginoso (EsCa), porção esternal (PEs) e porção intermediária da costela torácica (PInt).

Coracoide. 0 coracoide é um osso plano que apresenta duas faces (dorsal e ventral), duas margens (cranial e caudal) e duas extremidades (medial e lateral). Faz parte do cíngulo do membro torácico, juntamente com a escápula, e apresenta o eixo longitudinal dirigido transversalmente (mediolateralmente), enquanto o da escápula está posicionado perpendicularmente à superfície de apoio (proximal-distal) (Fig.5).

Hioide. 0 hioide consiste de uma placa de cartilagem, do corpo do hioide e de um par de cornos (Fig.6). 0 corpo do hioide é arredondado rostralmente e marcado por uma depressão caudal e duas incisuras laterais. Os cornos do hioide surgem na altura das incisuras, são parcialmente ossificados e se dirigem caudalmente.

Basioccipital e exoccipitais. Esses ossos, em conjunto, formam parte da parede caudal da cavidade craniana (Fig.7). 0 basioccipital é um osso único, que forma a mar-

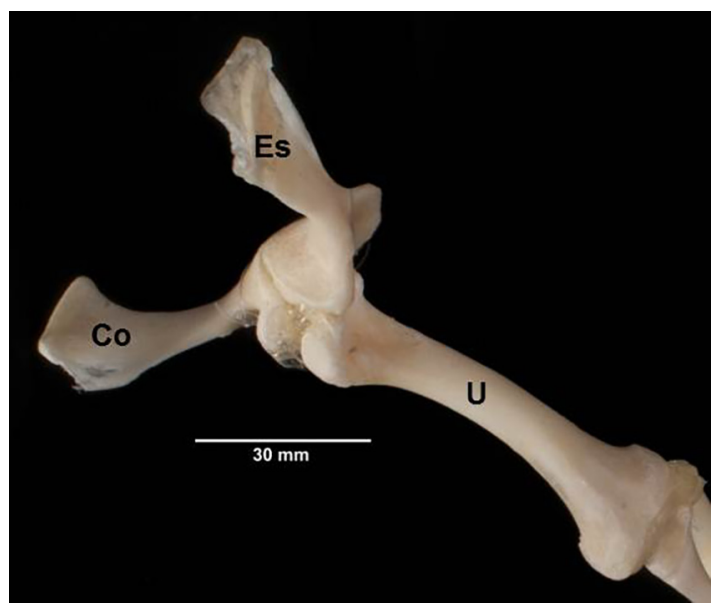

Fig.5. Cintura do membro torácico direito de Caiman yacare juvenil, vista caudal. Coracoide (Co), escápula (Es), úmero (U).

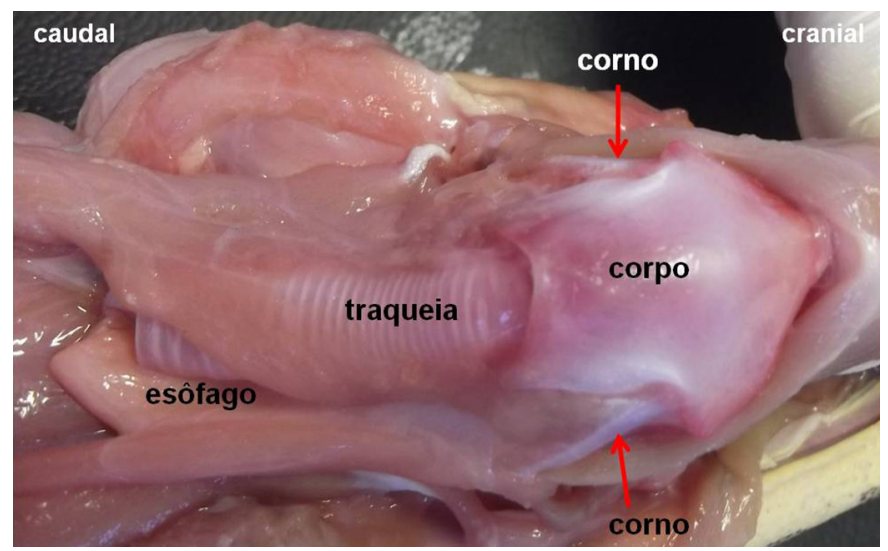

Fig.6. 0 hioide de Caiman yacare juvenil, vista ventral.

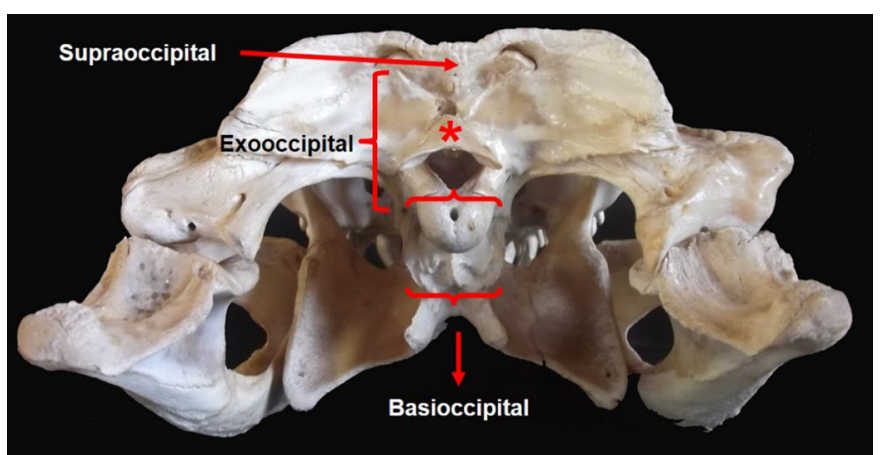

Fig.7. Crânio e mandíbula de Caiman yacare adulto, vista caudal. Pró-atlas $(*)$.

gem ventral do forame magno e o assoalho da parte caudal da cavidade craniana. Projeta-se caudalmente, com um único côndilo, e com uma porção irregular ventral ao mesmo côndilo. Os exoccipitais são ossos pares, apresentam uma porção dorsal lisa, em formato de asa, e uma porção ventral irregular que se articula medialmente com o basioccipital e lateralmente com o quadrado. Formam a margem dorsal e lateral do forame magno.

\section{Bases musculares do filé de dorso}

Os músculos, transverso espinhal da cabeça, transverso espinhal cervical, longuíssimo cervical, longuíssimo super- 
ficial da cabeça, longuíssimo profundo da cabeça, iliocostal cervical, escaleno, longo do pescoço, coracoceratoideo, esterno-hioideo, esternomastoide (esternoatlantical e atlantomastoide) e longo da cabeça constituem os músculos do filé de dorso.

Músculo transverso espinhal da cabeça (m. transversospinalis capitis). Constitui-se de duas partes: uma dorsal e superficial (medial), e outra localizada lateralmente à primeira.

a) Músculo transverso espinhal da cabeça - parte medial. Trata-se do músculo epaxial mais dorsal e superficial do pescoço (Fig.8). É bem desenvolvido e achatado dorsoventralmente; seu ventre conspícuo contrasta com os delgados feixes musculares, envoltos por aponeurose, que emergem de sua margem medial em direção aos pontos de fixação, na superfície dorsal do ápice, dos processos espinhosos das vértebras cervicais (da segunda à oitava). A margem lateral insere-se no ápice do processo espinhoso da nona VC e na fáscia superficial do pescoço, especialmente sua porção mais caudal. Os feixes musculares ancorados na primeira e segunda VC estão dispostos transversalmente, os demais, obliquamente. A fixação cranial deste músculo é na superfície dorsocaudal do pró-atlas, e por um tendão bem demarcado observam-se pontos de fixação na cabeça.

b) Músculo transverso espinhal da cabeça - parte lateral. É um músculo bem desenvolvido, situado na superfície dorsal do pescoço (Fig.8), profundamente à parte medial e dorsalmente ao músculo transverso espinhal cervical. Sua porção cranial é mais espessa e a parte caudal, parcialmente encoberta pela parte medial, é plana. A partir de sua inserção medial, os feixes musculares se reúnem para formar o ventre muscular, que confere o aspecto semilunar ao músculo. Feixes musculares mais superficiais se inserem juntamente com a aponeurose da parte medial, enquanto as fibras mais profundas se fixam, de forma serrilhada e direta (designada fixação carnosa), à superfície craniolateral dos processos espinhosos da segunda à sétima

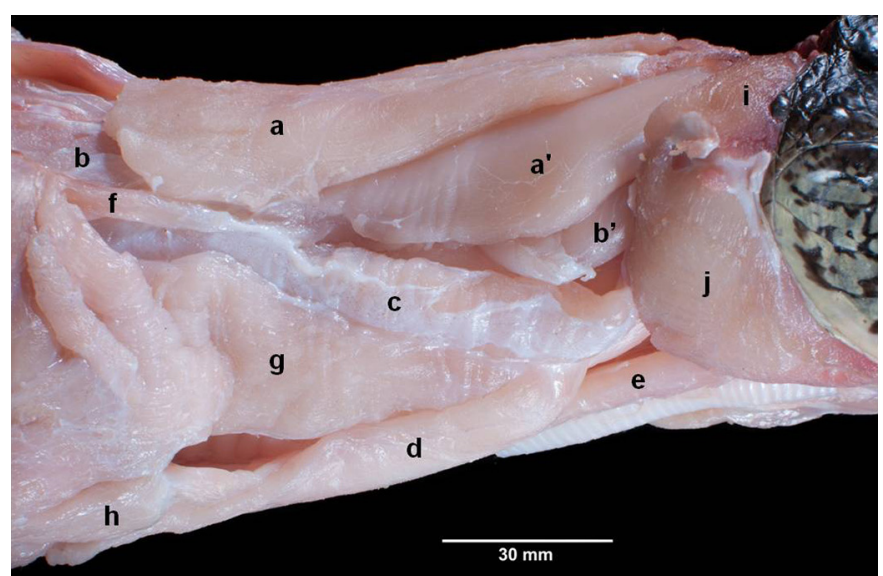

Fig.8. Pescoço de Caiman yacare juvenil, vista lateral direita dos músculos cervicais superficiais. Músculos: transverso espinhal da cabeça, parte medial (a) e parte lateral (a'); longuíssimo cervical (b), longuíssimo superficial da cabeça (b'), iliocostal cervical (c), esternoatlantical (c), esterno-hioideo (e), romboide (f), levantador da escápula (g), supracoracoideo (h), depressor da mandíbula (i), pterigoide ventral (j).
VC. Sua extremidade cranial se fixa na margem lateral das massas laterais do atlas, mas não foi possível verificar se há inserção no crânio. 0 feixe muscular mais caudal se insere na oitava VC, junto com o tendão do músculo transverso espinhal cervical. Sua margem lateral se insere na fáscia superficial do pescoço, junto com a porção medial.

Músculo transverso espinhal cervical (m. transversospinalis cervicis). É um músculo fino, localizado profunda e medialmente na parte lateral do músculo transverso espinhal da cabeça, entre este e o músculo longuíssimo cervical. Seu ventre é constituído por duas partes: uma dorsal (disposta medial e superficialmente) e outra ventral (lateral, plana e longa), parcialmente fusionadas. Os feixes musculares convergem em tendões que se fixam nos processos espinhosos da nona VC, primeira e segunda VT, e são contínuos ao músculo espinhal, porém, a separação entre eles não é nítida. A parte dorsal apresenta uma ancoragem cranial na terceira VC, ao nível da articulação com a terceira costela cervical. Na sua margem medial, tendões se inserem nos processos espinhosos da quinta à sétima VC e, na margem caudal, a inserção aponeurótica ocorre no processo espinhoso da oitava VC, juntamente com a parte lateral do músculo transverso espinhal da cabeça. A parte ventral se insere juntamente com a parte lateral do músculo transverso espinhal da cabeça, por meio de um forte tendão, na superfície lateral da massa lateral do atlas. A fixação medial da parte ventral se insere, por aponeurose, na superfície lateral dos processos articulares de todas as VC.

Músculo longuíssimo (m. longissimus). Constitui um sistema contínuo de musculatura epaxial, formado pelo músculo longuíssimo caudal, do tronco, cervical e da cabeça. Nas regiões da cauda e do tronco, esse músculo se apresenta na forma de cones de miossepto. Na região cervical, há uma modificação desse arranjo, onde a parte dorsal do cone de miossepto tem continuidade como músculo longuíssimo cervical, e a parte ventral constitui o músculo longuíssimo superficial e profundo da cabeça, além de contribuir com a formação do músculo iliocostal cervical.

a) Músculo longuíssimo cervical ( $m$. longissimus cervicis). É o mais dorsal dos três músculos longuíssimos na região cervical (Fig.8); localiza-se ventralmente ao músculo transverso espinhal cervical e dorsomedialmente ao músculo iliocostal cervical, com o qual reveste os músculos longuíssimo superficial e profundo da cabeça. Tem aspecto segmentado, com os tendões representando a parte dorsal dos cones de miossepto da região torácica. Sua margem medial se fixa por aponeurose, que se condensa, na superfície lateral dos processos articulares da segunda à nona VC, e as fibras se dirigem caudolateralmente. Um tendão forte se fixa à primeira VC. Sua margem lateral se fixa na fáscia do músculo iliocostal cervical, com difícil separação entre eles. Sua extremidade caudal é contínua ao conjunto de feixes dorsais do músculo longuíssimo do tronco.

b) Músculo longuíssimo superficial da cabeça ( $\mathrm{m}$. longissimus capitis superficialis). Corresponde à parte mais dorsal, medial e superficial do músculo longuíssimo da cabeça (Fig.8). Está localizado entre o músculo longuíssimo cervical (dorsocaudalmente) e o longuíssimo profundo da cabeça (ventrocaudalmente). Seu ventre, achatado 
dorsoventralmente, tem aspecto fusiforme cujas fibras se dirigem craniomedialmente. Sua margem medial e lateral se fixam, respectivamente, à superfície dorsal dos processos transversos, ao arco vertebral da quarta à nona VC e à fáscia superficial do pescoço. Sua extremidade caudal se afunila e se insere no processo transverso da nona VC.

c) Músculo longuíssimo profundo da cabeça ( $\mathrm{m}$. longissimus capitis profundus). É a parte mais ventral do músculo longuíssimo, na região cervical. Sua parte caudal se situa entre o músculo longuíssimo superficial da cabeça (dorsalmente) e o músculo iliocostal cervical (lateroventralmente). É bem desenvolvido, de aspecto fusiforme, em sua parte cranial, e achatado em sua parte caudal, que se insere no processo transverso da VC7. Suas fibras se dirigem cranioventral e lateralmente. Sua margem medial se fixa à superfície lateral do arco vertebral e à parte ventral do processo transverso, da VC3 à VC7, ao nível das articulações costovertebrais. Sua margem lateral se fixa à fáscia superficial do pescoço. A extremidade cranial se insere no osso basioccipital, ventrolateralmente ao côndilo e à porção atlantomastoide do músculo esternomastoide. Em sua face ventral, há uma aponeurose que se ancora na margem dorsal da primeira costela cervical.

Músculo iliocostal cervical (m. iliocostalis cervicis). É um músculo plano, segmentado (Fig.8), bem desenvolvido, em posição lateroventral na região cervical caudal, contínuo com o músculo iliocostal do tronco. Sua face lateroventral relaciona-se com o músculo levantador da escápula, e sua face medial com os músculos longuíssimo superficial e profundo da cabeça. As fibras musculares são demarcadas por septos intermusculares, com a presença de uma fáscia espessa em sua superfície lateral. No ponto da inserção medial do músculo romboide, feixes ventrais do músculo longuíssimo do tronco contribuem para a formação do músculo iliocostal cervical, o que dificulta a separação entre eles - fato evidenciado pela tênue presença do septo transverso - que, neste nível, se torna menos evidente, o que indica a mistura das fibras na formação do músculo iliocostal cervical. Sua margem ventral está fixada por meio de tendões que emergem dos feixes musculares e se inserem na superfície caudal das costelas cervicais, ao nível da articulação costovertebral e na superfície lateral dos processos transversos das VC. Há um tendão espesso na primeira costela cervical. Os tendões se dirigem caudodorsalmente, o que confere o aspecto segmentado acima descrito. Sua margem dorsal se insere na fáscia superficial do pescoço. Sua extremidade cranial se fixa por meio de uma fáscia contínua, que reveste a face medial da porção atlantomastoide do músculo esternomastoide, juntamente com os músculos levantador da escápula e a porção esternoatlantical do músculo esternomastoide. Sua extremidade caudal é contínua com o músculo iliocostal dorsal. Em $C$. yacare, as margens laterais dos músculos transverso espinhal da cabeça, transverso espinhal cervical, longuíssimo da cabeça (superficial e profundo) e a margem dorsal do músculo iliocostal cervical estão inseridas na fáscia superficial do pescoço.

Músculo escaleno (m. scalenus). Trata-se de um músculo plano triangular da região cervical, com a base volta- da caudalmente e o ápice cranialmente. É constituído por fibras dispostas longitudinalmente (craniocaudalmente) e está localizado entre o músculo serrátil superficial (dorsalmente) e o plexo braquial (ventralmente). Sua margem ventral se fixa por aponeurose à superfície lateral e ventral da terceira à nona costela cervical, com as fibras se inserindo nos tendões da costela imediatamente cranial a cada origem. Sua margem dorsal se fixa à fáscia do músculo serrátil superficial. Sua base está ancorada juntamente com a fáscia do músculo serrátil superficial, na superfície cranial e lateral da nona costela cervical. Seu ápice está ancorado na superfície lateral e ventral da terceira costela cervical.

Músculo longo do pescoço (m. longus colli). É um músculo robusto (Fig.9), com fibras dispostas obliquamente, localizado paralelamente à coluna vertebral, na superfície ventrolateral do pescoço e no teto da cavidade torácica, estendendo-se da primeira costela cervical até a quinta costela torácica. $\mathrm{Na}$ extremidade caudal, os músculos direito e esquerdo convergem medianamente, para se inserirem no processo ventral da oitava e nona VC e da primeira à quarta VT, o que confere convexidade ao seu contorno lateral. $\mathrm{Na}$ região cervical, localiza-se entre os músculos escaleno, serrátil superficial e iliocostal cervical (dorsalmente), levantador da escápula e coracoceratoideo (lateralmente), esternomastoide e esterno-hioideo (ventralmente). Sua margem medial se fixa por feixes aponeuróticos nos processos ventrais e superfície ventral dos corpos das vértebras cervicais da VC5 à VC9 e nas quatro primeiras VT. Sua fixação dorsal é na cabeça das costelas. Sua extremidade cranial se fixa à extremidade caudal da primeira costela cervical, juntamente com a origem do músculo levantador da escápula e a extremidade caudal da porção atlantomastoide do músculo esternomastoide.

Músculo coracoceratoideo ( $m$. coracoceratoideus). Trata-se de fino feixe muscular (Fig.9) que ocupa a superfície ventrolateral do pescoço, estendendo-se obliquamente do osso coracoide ao hioide. Neste trajeto, cruza a superfície dorsal do músculo esternomastoide (porção ester-

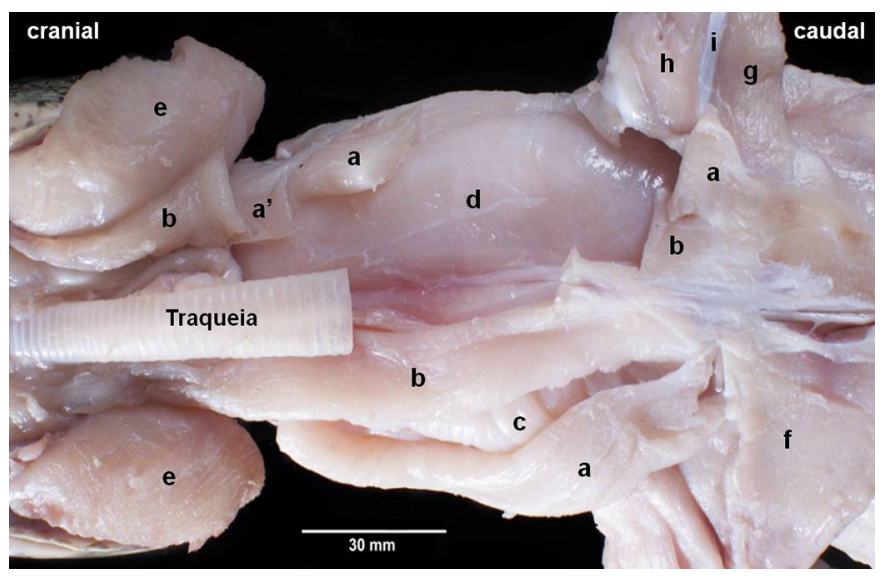

Fig.9. Pescoço de Caiman yacare juvenil, vista ventral. Músculos cervicais superficiais (antímero direito) e profundos (antímero esquerdo). Músculos: esternoatlantical (a), atlantomastoide (a'), esterno-hioideo (b), coracoceratoideo (c), longo do pescoço (d), pterigoide ventral (e), peitoral superficial (f), coracobraquial curto ventral $(\mathrm{g})$, supracoracoideo $(\mathrm{h})$. Tendão do bíceps braquial (i). 
noatlantical), paralelamente à face lateral do esôfago e da traqueia, e a face dorsal do músculo esterno-hioideo. Sua extremidade cranial se fixa à extremidade caudolateral do corno do hioide, juntamente com a inserção do músculo gênio-hioideo e profundamente à porção lateral do músculo esterno-hioideo. Sua extremidade caudal se insere na margem cranial do osso coracoide, junto com a origem do músculo supracoracoideo.

Músculo esterno-hioideo (m. sternohyoideus). É um músculo em forma de fita (Fig.8 e 9), cujas fibras estão dirigidas longitudinalmente. Está localizado na superfície ventral do pescoço, lateralmente à traqueia, ventralmente ao músculo longo do pescoço e medialmente aos músculos esternomastoide e coracoceratoideo. A extremidade caudal tem fixação muscular na extremidade cranial e superfície lateral do episterno, estendendo-se até a extremidade cranial do esterno cartilaginoso, entre a inserção dos músculos peitorais (superficial e profundo). A extremidade cranial bifurca-se em dois ramos musculares (medial e lateral). 0 medial fixa-se em dois pontos, no ângulo caudal do corpo do hioide e na margem ventral da porção cranial do corno do hioide, profundamente ao músculo gênio-hioideo. A parte lateral afunila-se formando um fino tendão.

Músculo esternomastoide (m. sternomastoideus). É um músculo de fibras paralelas, disposto obliquamente na superfície lateroventral do pescoço (Fig.8). É constituído por duas partes distintas.

a) Músculo esternoatlantical. Porção maior e mais caudal (Fig.8 e 9), de fibras orientadas craniolateralmente, localiza-se ventralmente ao músculo longo do pescoço. Sua superfície dorsal é cruzada obliquamente pelo músculo coracoceratoideo. Sua extremidade caudal tem fixação tendínea, no ângulo craniolateral do esterno cartilaginoso, lateroventral à origem do músculo esterno-hioideo e entre os músculos peitorais (superficial e profundo). Sua inserção cranial, na extremidade caudal da primeira e segunda costelas cervicais, propicia ancoragem para o músculo levantador da escápula e a porção atlantomastoide.

b) Músculo atlantomastoide. É um músculo plano (Fig.9), localizado lateralmente ao músculo longuíssimo profundo da cabeça, cranialmente ao músculo iliocostal cervical, ao músculo levantador da escápula e à porção esternoatlantical. A fáscia conspícua, localizada medialmente à parte atlantomastoide, propicia dois pontos de ancoragem para esse músculo: o primeiro fixa a margem ventral à superfície dorsolateral da primeira costela cervical; e o segundo, na extremidade caudodorsal, é contínuo ao músculo iliocostal cervical. Sua extremidade cranial se insere em uma saliência no osso exoccipital, ventrolateralmente ao forame magno.

Músculo longo da cabeça ( $m$. longus capitis). Músculo cilíndrico e curto, com fibras dispostas longitudinalmente. Localiza-se na superfície ventral do pescoço, em posição paramediana e ocupa os dois terços craniais dessa região. Está localizado cranialmente ao músculo longo do pescoço e medialmente à porção atlantomastoide do músculo esternomastoide. Na face dorsal, está associado aos corpos das vértebras cervicais e respectivos processos ventrais e, na face ventral, faz sintopia com o esôfago. Na extremidade cranial, os músculos direito e esquerdo configuram a letra Y, por sua inserção mediana conjunta. Sua face dorsal tem fixação tendínea, originada da própria fáscia, na superfície lateral do processo ventral da terceira à sétima VC. Sua extremidade cranial se insere no osso basioccipital, ventrolateralmente ao côndilo. Sua extremidade caudal apresenta a mesma forma de inserção da face dorsal, acrescida do compartilhamento da fáscia do músculo longo do pescoço.

\section{DISCUSSÃO}

\section{Bases ósseas do filé de dorso}

Os achados do basioccipital e exoccipital em C. yacare assemelham-se à descrição em A. mississippiensis (Reese 2000, Holliday 2011). No entanto, o hioide em C. yacare difere da descrição em $A$. mississippiensis, que possui o formato da letra L (Holliday 2011), porém, assemelha-se à de Reynolds apud Reese (2000) sobre crocodilianos. A organização do osso coracoide em C. yacare é similar à de outros crocodilianos e à da maioria dos tetrápodes (Meers 2003). Nos crocodilianos atuais, um único par de ossos coracoides está presente e corresponde ao par cranial dos anfíbios, que também apresentam outro par caudal (Hildebrand \& Goslow 2006).

A presença de nove VC em C. yacare corresponde ao encontrado em Alligator mississippiensis (Higgins 1923, Reese 2000) e em Crocodylia (Tsuihiji 2007); no entanto, difere dos resultados de Lima et al. (2011), que descreveram a esqueletogênese em embriões de $C$. yacare e consideram que a espécie tem oito VC. Tal inconsistência, provavelmente, se deve à dificuldade de identificação da primeira vértebra torácica, pois, no presente trabalho, utilizou-se o critério estabelecido por Baumel et al. (1993), que considera como primeira vértebra torácica a mais cranial, com um par de costelas que se articulam ao esterno, uma vez que isso as difere das cervicais, pois, apesar de apresentarem também costelas, não se articulam ao esterno. Tal interpretação foi também adotada por Reese (2000) e Tsuihiji (2007). De forma semelhante, Lane (2005) descreveu números variáveis de vértebras em crocodilianos, esclarecendo que a distinção entre as vértebras cervicais, torácicas e lombares não é clara e gera divergentes interpretações. A condição observada no C. yacare do pró-atlas independente e articulado com as massas laterais pode ocorrer em alguns reptilianos, uma vez que, na evolução dos tetrápodes, houve redução do tamanho do pró-atlas, que se fundiu parcialmente às unidades adjacentes (Hildebrand \& Goslow 2006). 0 grande centro vertebral (corpo) do áxis (Lima et al. 2011) é considerado por Hildebrand \& Goslow (2006) como a incorporação do corpo do atlas pelo áxis, que poderia ser representado pela demarcação existente entre a porção cranial e o restante do corpo do áxis. As formas das superfícies articulares das extremidades dos corpos vertebrais apresentam função evolutiva, funcional e sistemática (Hildebrand \& Goslow 2006). No jacaré-do-pantanal, o corpo vertebral da terceira à nona VC é procélico, ou seja, côncavo na extremidade cranial e convexo na caudal, condição observada na maioria dos répteis, que permite movimento em qualquer direção e resistência ao deslocamento (Hildebrand \& Goslow 2006). 0 arranjo observado em C. yacare, 
entre as costelas cervicais e respectivas vértebras, assemelha-se ao descrito em crocodilianos por Snively \& Russell (2007), assim como a descrição das vértebras torácicas ao descrito por Reese (2000) em A. mississippiensis.

\section{Bases musculares do filé de dorso}

Uma divisão do músculo transverso espinhal da cabeça (medial e lateral) já foi evidenciada em A. mississippiensis e Caiman crocodilus (Snively \& Russell 2007, Tsuihiji 2010). A denominação do músculo transverso espinhal da cabeça, em C. yacare, seguiu ao estabelecido por Tsuihiji (2010). Este autor considerou que a parte medial desse músculo em crocodilianos (Alligator mississippiensis, Caiman crocodilus e Osteolaemus tetraspis) é homólogo ao músculo biventer cervical em aves (Struthio camelus, Rhea americana, Meleagris gallopavo, Gallus sp. e Pygoscelis sp.), enquanto, a parte lateral é homóloga ao músculo complexo. Em lepidosauros (Sphenodon punctatus, Iguana iguana, Varanus exanthematicus e V. salvadorii), o músculo transverso espinhal da cabeça é denominado músculo espinhal da cabeça (Tsuihiji 2010).

Em C. yacare, o músculo transverso espinhal cervical apresenta duas partes e difere do complexo muscular descrito em A. mississippiensis (Seidel 1978), em que, na transição da região dorsal para a cervical, esse músculo é contituído pela união dos músculos multífidos, espinhal, articuloespinhal e tendinoarticular. Esses dois últimos músculos equivalem ao semiespinhal dos lepidosaurianos, em que o músculo tendinoarticular foi considerado um derivado do músculo semiespinhal (Gasc 1981). Em C. yacare, o músculo semiespinhal localiza-se somente nas regiões do tronco (Figueiredo et al. 2015b) e cauda (Figueiredo et al. 2015a).

O músculo longuíssimo é um complexo de músculos (longuíssimo cervical, longuíssimo superficial da cabeça e longuíssimo profundo da cabeça) semelhante ao descrito sobre a região cervical de $A$. mississippiensis (Tsuihiji 2007). Esse autor afirma que a arquitetura básica do grupo muscular longuíssimo cervical e dorsal em Crocodylia, tal como em Lepidosauria, é uma repetição segmentar dos tendões ligados por fibras musculares, em que cada tendão é tipicamente em forma de cone com o vértice direcionado caudalmente, como observado em $C$. yacare também nas regiões caudal (Figueiredo et al. 2015a) e do tronco (Figueiredo et al. 2015b), exceto nos componentes longuissimo superficial e profundo da cabeça, que possuem aspecto fusiforme nesta região. Essa semelhança se estende também para os pontos de ancoragem das fibras musculares (da quarta à nona VC), mas diferem do descrito por Seidel (1978), que relatou origens destas fibras da VC5 à VC8, em A. mississippiensis. Diferentemente da fixação medial do músculo longuíssimo profundo da cabeça (de VC3 a VC7), em $C$. yacare, Tsuihiji (2007) descreveu em A. mississippiensis e C. crocodilus sua fixação na superfície lateral dos arcos neurais, ventralmente ao septo intermuscular dorsal e aos processos transversos, com contribuições dos processos transversos de VC8. Para Frey (1988), esse músculo se estende de VC1 até VC7, e Seidel (1978) reconheceu pequenas contribuições dos processos transversos de VC8 e VC9.
Para Tsuihiji (2007), há homologia de morfologia dos músculos iliocostal (cervical e dorsal) entre Lepidosauria e Crocodylia. Nishi (1938) e Tschanz (1986) reconheceram em Lepidosauria três músculos do grupo iliocostal (da cabeça, cervical e dorsal), cuja divisão baseou-se, respectivamente, nos locais de inserção, a saber: occipital, nas costelas cervicais e costelas dorsais. Refere-se, ainda, que esses músculos também foram descritos em crocodilianos por Seidel (1978), que identificou o feixe mais anterior do músculo iliocostal cervical como músculo iliocostal da cabeça, conectando a primeira costela cervical ao occipital. No presente trabalho, não foi identificado em C. yacare o músculo iliocostal da cabeça, assim como Vallois (1922) e Frey (1988), que também não reconheceram esse músculo em crocodilianos. Em C. yacare, denominou-se o músculo localizado cranialmente ao músculo iliocostal cervical de músculo atlantomastoideo, por ser parte do músculo esternomastoide, à semelhança do descrito por Fürbringer (1876) sobre crocodilianos, ao invés de músculo iliocostal da cabeça. À semelhança do descrito sobre A. mississippiensis (Tsuihiji 2007) observou-se em $C$. yacare uma mistura de fibras do músculo iliocostal cervical com as do músculo longuíssimo do tronco.

Tsuihiji (2007) observou, em A. mississippiensis, que fibras do músculo escaleno se fixam à superfície lateral e ventral, da terceira à oitava costela cervical, e às superfícies caudal e lateral da nona costela cervical. Para o autor, embora o músculo escaleno seja considerado derivado da parte ventral do músculo intercostal externo cervical, ele não apresenta o mesmo aspecto metamérico e é facilmente distinguível desse músculo, tal como observado nesta pesquisa em C. yacare.

Schwarz et al. (2007) e Tsuihiji (2007) descrevem o músculo longo do pescoço em crocodilianos como parte da musculatura subvertebral de aspecto não segmentado. A fixação ocorre à superfície lateral dos processos ventrais e à superfície ventral do corpo das vértebras cervicais e torácicas craniais, além das costelas cervicais, assemelhando-se ao observado em C. yacare. Esse arranjo difere nas aves, em que esse músculo, além da porção ventral, tem uma dorsal como consequência do processo de alongamento e sinuosidade dessa região neste táxon (Snively \& Russell 2007). Esses autores sugerem, ainda, que essa seja a condição ancestral no arcossauros.

Para Snively \& Russell (2007), em crocodilianos, o músculo longo da cabeça corresponde ao músculo flexor do pescoço em aves e está associado com os processos ventrais e a superfície ventral dos corpos das VC, à semelhança do observado em $C$. yacare.

Os músculos coracoceratoideo e esterno-hioideo correspondem à descrição de Reese (2000), sobre A. Mississippiensis, respectivamente, aos músculos omohioide/coracohioide e episternoceratoideo/esterno-hioideo.

\section{CONCLUSÕES}

No Caiman yacare, as vértebras e costelas cervicais, vértebras e costelas torácicas, esterno, coracoide, hioide, basioccipital e exoccipital servem de base para a fixação da musculatura que compõe o corte filé de dorso. 
No Caiman yacare, o corte comercial filé de dorso é constituído pelos músculos transverso espinhal da cabeça, transverso espinhal cervical, longuíssimo cervical, longuíssimo superficial da cabeça, longuíssimo profundo da cabeça, iliocostal cervical, escaleno, longo do pescoço, coracoceratoideo, esterno-hioideo, esternomastoide e longo da cabeça.

Os músculos intertransversais cervicais e os intercostais externos cervicais, embora integrantes da musculatura cervical, não participam do corte filé de dorso porque não são desossados.

Os músculos longuíssimo cervical e iliocostal cervical apresentam os ventres musculares interpostos por septos conjuntivos, que lhes conferem aspecto segmentado em toda a extensão. Os demais músculos apresentam ventres musculares não segmentados.

Os músculos transverso espinhal da cabeça, longo do pescoço e coracoceratoideo apresentam fibras dispostas obliquamente, enquanto nos demais predominam fibras longitudinais.

Agradecimentos.- À Coordenação de Aperfeiçoamento de Pessoal de Nível Superior (CAPES), pelo apoio financeiro; à Cooperativa dos Criadores de Jacaré-do-pantanal (COOCRIJAPAN), pela doação dos exemplares utilizados no estudo; e ao fotógrafo Lucas Ninno, sem quem não conseguiríamos compartilhar a riqueza dos detalhes anatômicos do jacaré-do-pantanal.

\section{REFERÊNCIAS}

Baumel J.J., King A.S., Breazile J.E., Evans H.E. \& Vanden Berge J.C. 1993. Handbook of Avian Anatomy: Nomina Anatomica Avium. 2nd ed. Nuttall Ornithological Club, Cambridge. 779p.

Coocrijapan 2013. Cooperativa dos Criadores de Jacaré-do-Pantanal - coocrijapan@coocrijapan.com.br. Dados sobre a produção e comercialização. Mensagem recebida por Figueiredo S.I.S. (sandrafigueiredo@ufmt. br). Acesso em 21 maio 2013.

Figueiredo S.I.S., Araújo E.G., Araújo L.B.M. \& Ferraz R.H.S. 2015a. Bases ósseas e musculares dos cortes comerciais da cauda de jacaré-doPantanal (Caiman yacare Daudin 1802). Arq. Bras. Med. Vet. Zootec. 67(3):909-917.

Figueiredo S.I.S., Araújo L.B.M., Ferraz R.H.S., Guimarães F.R., Cantarini J.L. \& Araújo E.G. 2015b. Bases ósseas e musculares dos cortes comerciais do tronco de jacaré-do-Pantanal (Caiman yacare Daudin, 1802). Pesq. Vet. Bras. 35(8):749-761.

Frey E. 1988. Das Tragsystem der Krokodile: eine biomechemische und phylogenetische Analyse. Stuttgarter Beiträge zur Naturkunde A, Biologie, 426:1-60.

Fürbringer M. 1876. Zur vergleichenden Anatomie der Schultermuskeln. III. Theil. Morph. Jahrb. 1:636-816.

Gasc J.-P. 1981. Axial musculature, p.355-435. In: Gans C. \& Parsons T.S. (Eds), Biology of the Reptilia. Vol.11. Academic Press, London. 475p.

Higgins G.M. 1923. Development of the primitive reptilian vertebral column, as shown by a study of Alligator mississippiensis. Am. J. Anat. [online] 31(4): 373-407. Disponível em <http://onlinelibrary.wiley.com/ doi/10.1002/aja.1000310405/pdf> Acesso em: 18 mar. 2013.

Hildebrand M. \& Goslow. G.E. 2006. Esqueleto do corpo, p.141-167. In: Ibid. (Eds), Análise da Estrutura dos Vertebrados. $2^{\underline{a}}$ ed. Atheneu, São Paulo. 638p.

Holliday C.M. 2011. 3D Database of the cranial bones of the American alligator (Alligator mississippiensis). Vertebrate Functional Morphology and Evolution, Holliday Lab and Witmer Lab. Disponível em <http://web.
missouri.edu/hollidayca/3DAnatomy/Alligator3D.htm> Acesso em 11 jul. 2011.

International Committee on Veterinary Gross Anatomical Nomenclature ICVGAN 2012. Nomina Anatomica Veterinaria. [online]. 5th revised ed. Editorial Committee, Hannover. Disponível em <http://www.wavaamav.org/Downloads/nav_2012.pdf> Acesso em 26 abr. 2013.

Lane T.J. 2005. Crocodilians, p.78-94. In: Mader D.R. (Ed.), Reptile Medicine and Surgery. W.B. Saunders Company, Philadelphia. 1242p.

Lima F.C., Vieira L.G., Santos A.L.Q., Pereira H.C., Alves P.H.M. \& Assumpção T.I. 2011. Esqueletogênese dos ossos da coluna vertebral, costelas e esqueleto abdominal em embriões de Caiman yacare (Crocodylia: Alligatoridae). Biosci. J. 27(5):813-825.

Meers M.B. 2003. Crocodylian forelimb musculature and its relevance to Archosauria. Anat. Rec. A 27(4):891-916.

Nishi S. 1938. Muskeln des Rumpfes, p.351-446. In: Bolk L., Göppert E., Kallius E. \& Lubosch W. (Eds), Handbuch der vergleichenden Anatomie der Wirbeltiere. Band 5. Urban und Schwarzenberg, Berlin.

Piran C. 2010. Proposta para a gestão de qualidade e de segurança do alimento da unidade processadora de carne de jacaré da Coocrijapan. Dissertação de Mestrado em Engenharia de Produção, Universidade Federal de São Carlos, São Carlos, SP. 153p.

Reese A.M. 2000. The alligator and its allies. [online]. Landisville: Arment Biological, Disponível em <www.herper.com/ebooks> Acesso em 20 ago. 2009.

Rodrigues E.C., Bressan M.C., Vicente Neto J., Oliveira e Vieira J., Farias P.B., Ferrão S.P.B. \& Andrade P.L. 2007. Qualidade e composição química de cortes comerciais de carne de jacaré-do-Pantanal (Caiman yacare). Ciênc. Agrotec. 31(2):448-455.

Romanelli P.F., Cesari R. \& Lima Filho J.F. 2002. Processamento da carne do jacaré-do-Pantanal (Caiman crocodillus yacare). Ciênc. Tecnol. Aliment. 22(1):70-75.

Schwarz D., Frey E. \& Meyer C.A. 2007. Pneumaticity and soft-tissue reconstruction in the neck of diplodocid and dicraeosaurid sauropods. Acta Palaeontol. Pol. 52(1):167-188.

Seidel M.R. 1978. The somatic musculature of the cervical and occipital regions of Alligator mississippiensis. PhD Dissertation, The City University of New York, New York, USA. 339p.

SFA/MT 2013. Dados sobre a produção de cortes de jacaré em entrepostos de pescado sob SIF (Serviço de Inspeção Federal). Superintendência Federal da Agricultura, Pecuária e Abastecimento no Estado de Mato Grosso. Mensagem recebida por Figueiredo S.I.S. (sandrafigueiredo@ufmt. br). Acesso em 27 mar. 2013.

Silva E.M., Dias G., Tavares M., Marques T. \& Furtado J.M. 2008. Estudo analítico da técnica de glicerinação empregada para conservação de peças anatômicas - experiência da disciplina de anatomia humana do departamento de morfologia do UniFOA. Cadernos UniFOA 3.

Snively E. \& Russell A.P. 2007. Functional morphology of neck musculature in the Tyrannosauridae (Dinosauria, Theropoda) as determined via a hierarchical inferential approach. Zool. J. Linn. Soc. 151:759-808.

Tschanz K. 1986. Funktionelle Anatomie der Halswirbelsäule von Tanystropheus longobardicus (Bassani) aus der Trias (Anis/Ladin) des Monte San Giorgio (Tessin) auf der Basis vergleichend morphologischer Untersuchungen an der Halsmuskulatur rezenter Echsen. PhD Dissertation, Universität Zürich. 109p.

Tsuihiji T. 2007. Homologies of the longissimus, iliocostalis, and hypaxial muscles in the anterior presacral region of extant diapsida. J. Morphol. 268:986-1020.

Tsuihiji T. 2010. Reconstructions of the axial muscle insertions in the occipital region of dinosaurs: Evaluations of past hypotheses on Marginocephalia and Tyrannosauridae using the extant phylogenetic bracket approach. Anat. Rec. 293:1360-1386.

Vallois H.V. 1922. Les transformations de la musculature del'episome chez les vertebrés. Archs Morph. Gén. Exp. 13:1-538. 